\title{
Penerapan Pendekatan "Human Behavior" pada Gedung Pusat Kerajinan Tangan Anak Jalanan
}

\author{
Nurmaya Aini dan Purwanita Setijanti \\ Departemen Arsitektur, Fakultas Arsitektur, Desain dan Perencanaan, Institut Teknologi Sepuluh Nopember (ITS) \\ e-mail: psetijanti@arch.its.ac.id
}

\begin{abstract}
Abstrak-Didalam proses perancangan arsitektur merancang terdapat berbagai macam pendekatan perancangan. Adapun pendekatan yang dipilih adalah menggunakan pendekatan Human Behavior (perilaku manusia), untuk Gedung Pusat Kerajinan Anak Jalanan. Pemilihan tersebut dikhususkan untuk anak jalanan yang memiliki karakter berbeda dengan anak pada umumnya. Gedung Pusat Kerajinan yang dimaksud adalah tempat untuk mewadahi kreatifitas anak jalanan yang berlangsung kegiatan bisnis kerajinan tangan mulai dari produksi sampai ke pemasarannya secara online yang bertujuan untuk mempertahankan pola kehidupan sehari - hari yang melibatkan interaksi dengan anak nonjalanan. Adapun metode perancangan yang digunakan yaitu metode Behavior Mapping dalam menyelaraskan konsep desain yang sesuai dengan karakter anak jalanan. Isu yang dipilih akan diwujudkan melalui bentuk dan penataan ruang dalam. Hasil rancangan berupa bangunan yang mengambil karakter dari anak jalanan aktif dan kreatif, mandiri dan bebas, serta adaptif dengan lingkungan.
\end{abstract}

Kata Kunci-anak jalanan, behavior mapping, human behavior

\section{PENDAHULUAN}

$\mathrm{F}$ ENOMENA merabaknya anak jalanan di Indonesia merupakan permasalahan yang kompleks. Perkembangan anak jalanan di berbagai kota besar semakin hari semakin meningkat jumlahnya. Di tahun 2012, berdasarkan hasil Susenas yang diselenggarakan oleh BPS \& Pusdatin Kementrial Sosial tercatat sebanyak 94,674 anak jalanan di Indonesia. Terjadi peningkatan 64\% anak jalanan dari $2012-$ 2016 atau rata-rata sekitar $10.6 \%$ per tahun peningkatannya. Menurut Departemen Sosial RI (2015:5), anak jalanan adalah anak yang menghabiskan sebagian besar waktunya untuk melakukan kegiatan hidup sehari - hari di jalanan, baik untuk mencari nafkah atau berkeliaran di jalan tempat-tempat umum lainnya. Menurut Departemen Sosial RI (2010: 23-24), indikator usia mereka berkisar antara 6 tahun sampai 18 tahun [1].

Dalam mengatasi merabaknya perkembangan anak jalanan di Indonesia. Sebenarnya sudah dilakukan oleh pemerintah tentang kebijakan - kebijakan penanganan anak jalanan. Namun ternyata masih belum bisa menjangkau anak jalanan secara keseluruhan. Salah satu penyebabnya adalah masih kurangnya fasilitas yang tersedia [2]. Berdasarkan kasus yang diangkat yaitu tentang merabaknya anak jalanan, maka dapat dikaitkan dengan adanya ruang dan manusia di dalamnya. Anak jalanan selaku sebagai manusia yang memanfaatkan ruang jalanan untuk bertahan hidup dengan berbagai usaha yang dilakukannya dapat diangkat sebagai isu arsitektural yang dapat dipecahkan. Ruang jalanan yang sudah menjadi kebiasaan sehari - harinya dapat dialihkan melalui ruang arsitektur yang lebih layak dan terarah, tetapi masih menggunakan atau memanfaatkan nuansa ruang jalanan yang sudah melekat dalam dirinya. Dari penjelasan potensi anak jalanan menurut konsep BKSN (2000;hal. 111-112) dapat diidentifikasi perilaku khusus yang dimiliki oleh anak jalanan yaitu aktif dan kreatif (kehidupan jalanan memaksa mereka harus aktif melakukan apa saja untuk dapat bertahan hidup), mandiri dan bebas (tidak adanya perlindungan dari orang tua dan masyarakat terus menuntut untuk memenuhi kebutuhan sendiri), serta adaptif dengan lingkungan (mereka mampu bertahan dalam persaingan di jalanan dengan kebiasaan yang mengharuskan mereka cepat menyesuaikan diri dan berbaur dengan lingkungan) [1]. Agar mampu menciptakan desain yang dapat menyelesaikan masalah - masalah tersebut, penulis mencoba menerjemahkan permasalahan sosial ke dalam kerangka berpikir Philip Plowright dalam bukunya Revealing Architecture menjadi permasalahan arsitektural dan responnya (Gambar 1).

Dari analisa yang telah dilakukan, maka permasalahan merabaknya anak jalanan dapat diatasi dengan gedung bisnis yang merujuk pada pusat kerajinan anak jalanan. Merupakan tempat untuk mewadahi kreatifitas anak jalanan dimana berlangsung kegiatan bisnis kerajinan tangan mulai dari produksi sampai ke pemasarannya secara online yang dapat mengembangkan karakter khusus anak jalanan melalui program pendidikan informal, pembinaan, dan pelatihan dengan tujuan untuk memenuhi hak - hak yang dimiliki anak jalanan dalam upaya untuk bertahan hidup dan berinteraksi dengan anak lainnya. Gedung tersebut dirancang dengan Pendekatan Human Behavior". Pendekatan Human Behavior di dalam proses perancangan arsitektur menekankan pada keterkaitan antara ruang dengan manusia di dalamnya (anak jalanan) [3]. Aspek fisik lingkungan (dimensi lingkungan), kondisi psiokologis (dimensi personal), dan siklus waktu (dimensi waktu) yang dimiliki anak jalanan akan merujuk pada kecenderungan kriteria objek rancang. Kemudian diselaraskan dengan karakter anak jalanan pada konsep perancangan dalam menghasilkan Gedung Pusat Kerajinan Tangan Anak Jalanan.

\section{METODE PERANCANGAN}

Metode behavioral mapping merupakan metode yang digunakan untuk merekam aktivitats seseorang atau sekelompok orang disuatu tempat (ruang) dalam jangka waktu tertentu [4]. 


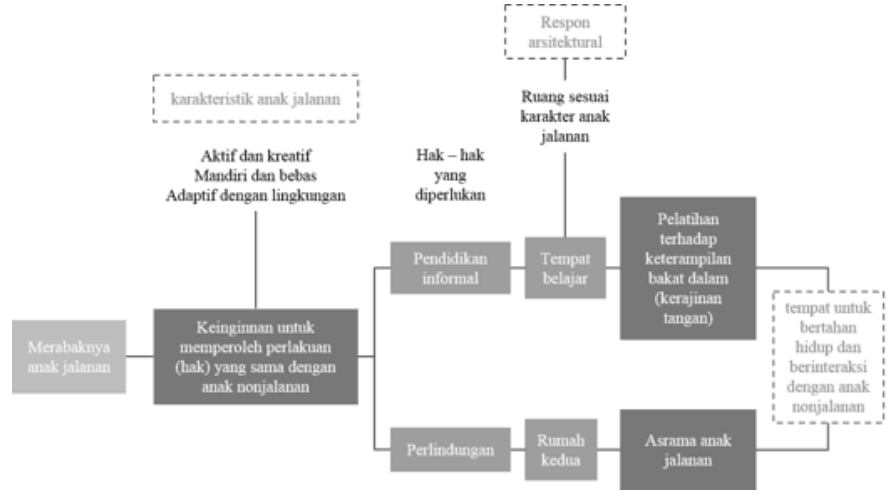

Gambar 1. Domain to domain transfer

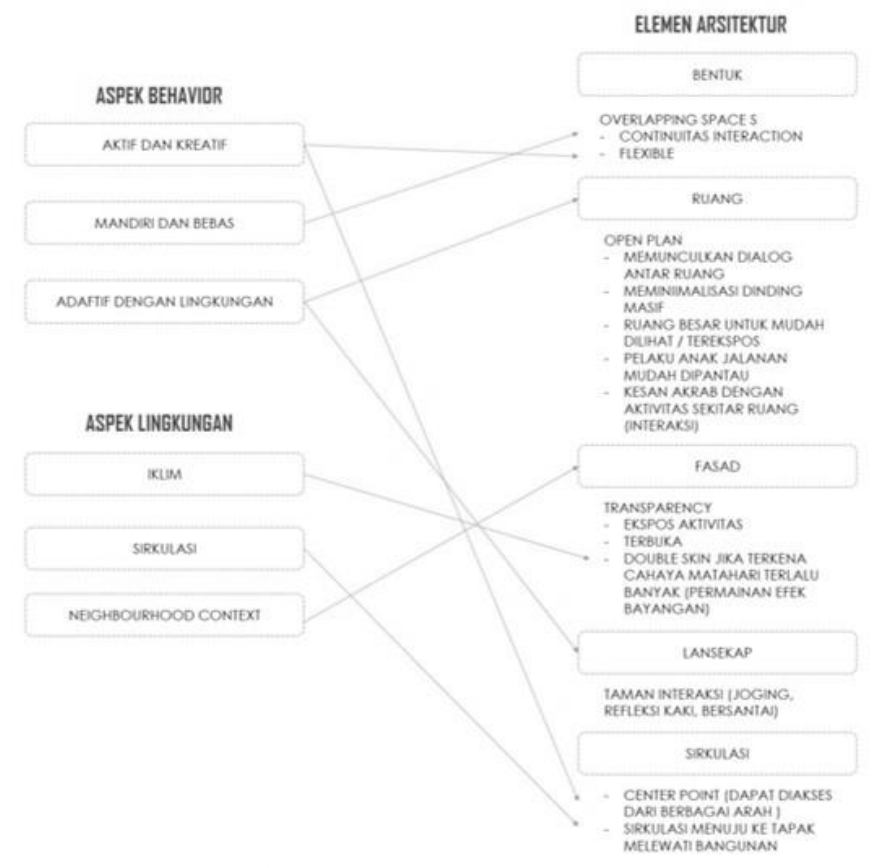

Gambar 2. Konsep desain.
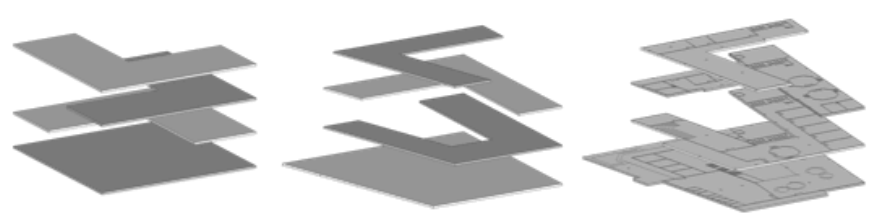

Gambar 3. Overlapping spaces penyesuaian dengan tapak.

Pemetaan perilaku meliputi peta kenyataan atau rencana dari suatu area pada lokasi manusia dan area menunjukkan aktivitas manusia, pengamatan terhadap perilaku pengguna ruang atau bangunan berdasarkan person-centered maps, place-centered maps, dan phisycal trace.

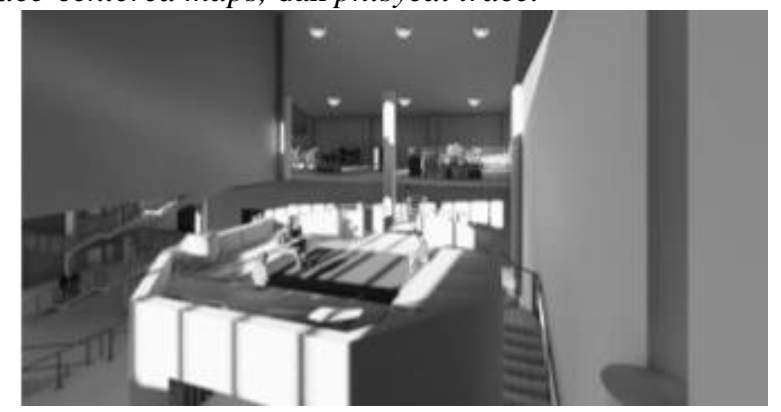

Gambar 4. Overlapping spaces pada ruang belajar.

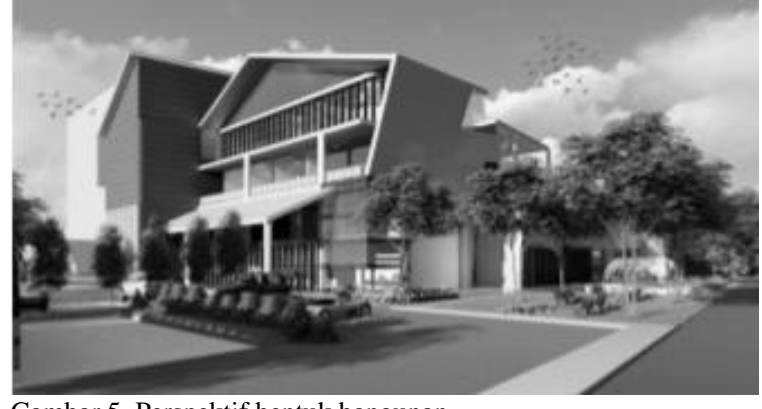

Gambar 5. Perspektif bentuk bangunan.

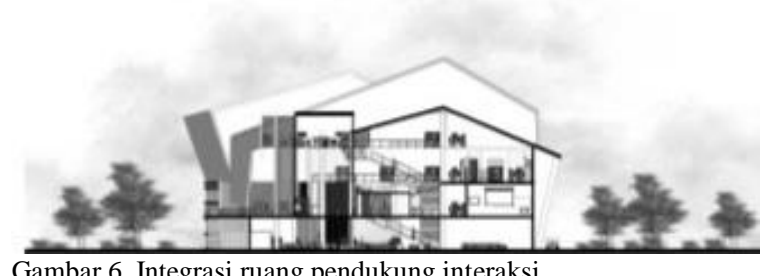

Gambar 6. Integrasi ruang pendukung interaksi.

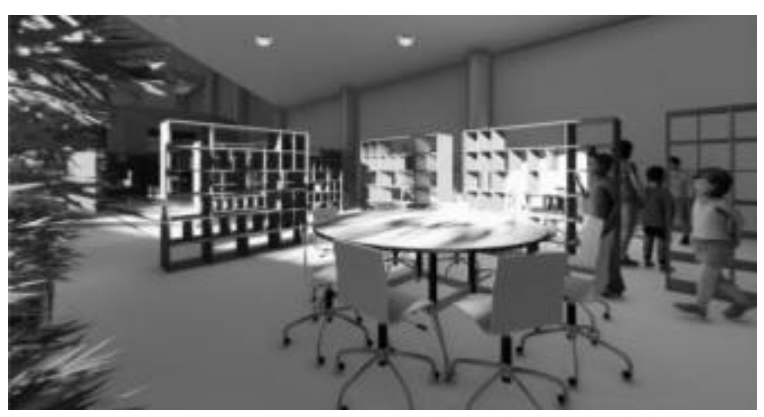

Gambar 7. Openplan pada ruang kerajinan dengan partisi rak buku.

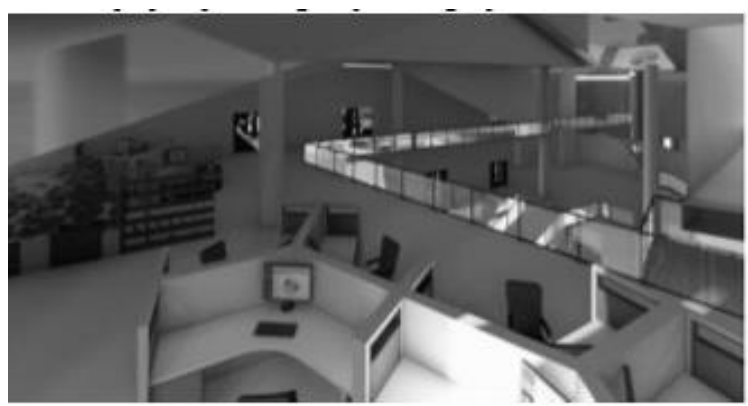

Gambar 8. Openplan pada ruang pemasaran kerajinan.

\section{Person-Centered Maps}

Teknik survei perilaku dengan menentukan pergerakan anak jalanan pada suatu periode waktu tertentu. Dalam obyek rancang bertujuan untuk mendapatkan pemetaan terhadap anak jalanan sebagai pengguna bangunan dan mengGambarkan pola perilaku anak jalanan dan aktivitasnya.

\section{Place-Centered Maps}

Metode ini digunakan untuk melihat bagaimana manusia mengatur dirinya dalam suatu lokasi tertentu (Sommer dkk, 1980). Teknik survei ini bertujuan untuk mengetahui bagaimana anak jalanan atau sekelompok anak jalanan

memanfaatkan, menggunakan atau mengakomodasikan perilakunya dalam suatu situasi waktu dan tempat tertentu. 


\section{Phisycal Trace.}

Pengamatan ini bertujuan untuk mendapatkan tanda tanda yang ditinggalkan anak jalanan setelah melakukan aktivitas. Tanda - tanda ini sebagai alat bantu dalam menganalisa hasil pengamatan tersebut.

Ketiga langkah tersebut kemudian akan membantu dalam penerapan metode behavior mapping dalam penentuan sirkulasi ruang dan kebutuhan ruang pada objek rancangan. Pola kegiatan sosial anak jalanan yang mencerminkan karakter anak jalanan akan tetap dipertahankan dalam obyek rancang yaitu dengan menghadirkan ruang - ruang berkumpul serta sirkulasi yang lebar sebagai ruang untuk kegiatan informal [5].

\section{HASIL DAN EKSPLORASI}

Hasil akhir perancangan ini menggunakan konsep yang memanfaatkan aspek behavior dalam membentuk elemen arsitektur yang sesuai dengan karakter anak jalanan. Adapun Gambaran besar konsep adalah sebagai berikut (Gambar 2).

1. Bentuk

Massa bangunan didesain menjadi dua massa. Massa pertama merupakan area kerajinan sedangkan massa ke dua merupakan area asrama. Massa utama didesain dengan konsep overlapping spaces (Gambar 3) dimaksudkan untuk memunculkan continuitas interaction (interaksi berkelanjutan) dan lebih fleksibel (Gambar 4). Hal ini sesuai dengan karakter anak jalanan aktif dan bebas.

Sedangkan bentuk bangunan didesain menyerupai rumah dimaksudkan sebagai rumah kedua anak jalanan yang lebih homey seperti rumah sendiri yang memunculkan kesan aman dan nyaman (Gambar 5). Selain itu juga dimaksudkan agar selaras dengan bangunan sekitar yang merupakan daerah perkampungan. Sehingga karakter anak jalanan yang adaptif dengan lingkungan tercapai.

2. Ruang

Sebagai wadah untuk aktivitas aktif yang dilakukan secara berkelompok, konsep integrasi ruang dibuat agar setiap ruang dapat saling terbuka dan berinteraksi secara visual. Hal ini sesuai dengan karakter anak jalanan yaitu adaptif dengan lingkungan. Penerapan openplan pada area utama kerajinan hanya menggunakan dinding - dinding partisi yang transparan sebagai pemisah ruang, menciptakan atmosfer terbuka tanpa mengesampingkan aspek privasi setiap pengguna ruang (Gambar 6).

Perbedakan jenis ruang - ruang terikat dalam satu ruang openplan (Gambar 7), digunakan permainan skala ruang seperti permainan ketinggian plafon ataupun lantai dan material ruang di masing - masing zona disesuaikan dengan karakter masing - masing ruang.

Pola tata ruang yang dipilih adalah open plan, karena yang paling mendekati dengan dasar pertimbangan perilaku anak jalanan yang bebas namun membutuhkan pengawasan dan perlindungan. Dalam susunan ini, ruang tidak dipisah pisahkan atau tidak menggunakan penyekat, tetapi semua aktivitasnya dilaksanakan pada satu ruang besar terbuka sehingga semua yang bekerja tampak mudah diamati dari satu sudut pandang. Bentuk ruang ini memeberi kesan akrab dan kebersamaan maka cocok untuk ruang kerja (Gambar 8).

3. Fasad

Fasad bangunan menghadap ke jalan utama yaitu Jalan Jagir Wonokromo di arah utara tapak (Gambar 10). Fasad bangunan secara dominan menggunakan material kaca transparan untuk mengekspos aktivitas yang terjadi di dalam bangunan guna mencerminkan karakter anak jalanan yang adptif dengan lingkungan (Gambar 11). Selain itu, fasad bangunan juga tertutupi oleh dinding masif yang memang sengaja untuk tidak mengekspos aktivitas di dalam bangunan yang bersifat lebih privat (Gambar 12).

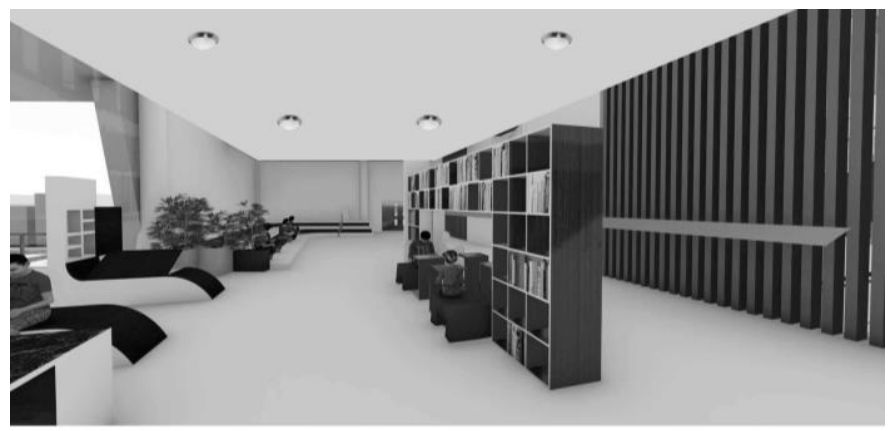

Gambar 9. Open plan pada perpustakaan

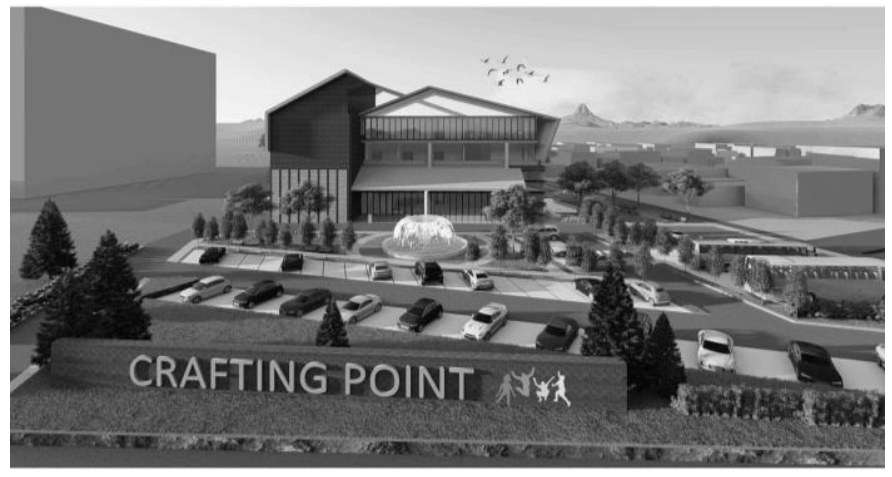

Gambar 10. Perspektif sisi depan bangunan

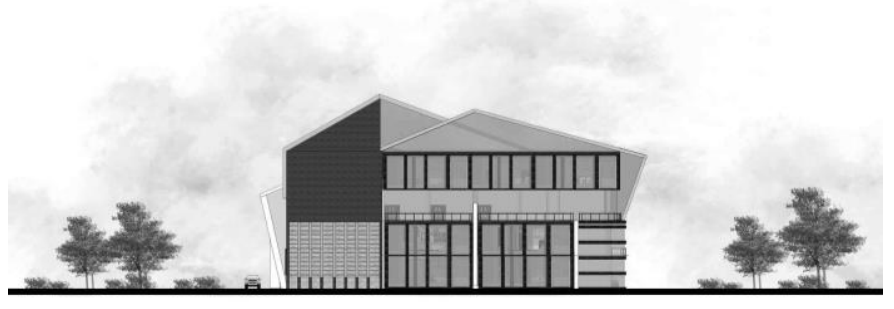

Gambar 11. Tampak utara.

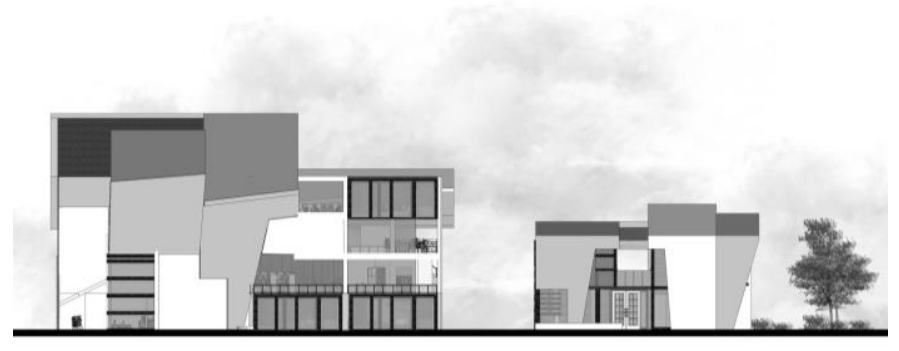

Gambar 12. Tampak barat. 


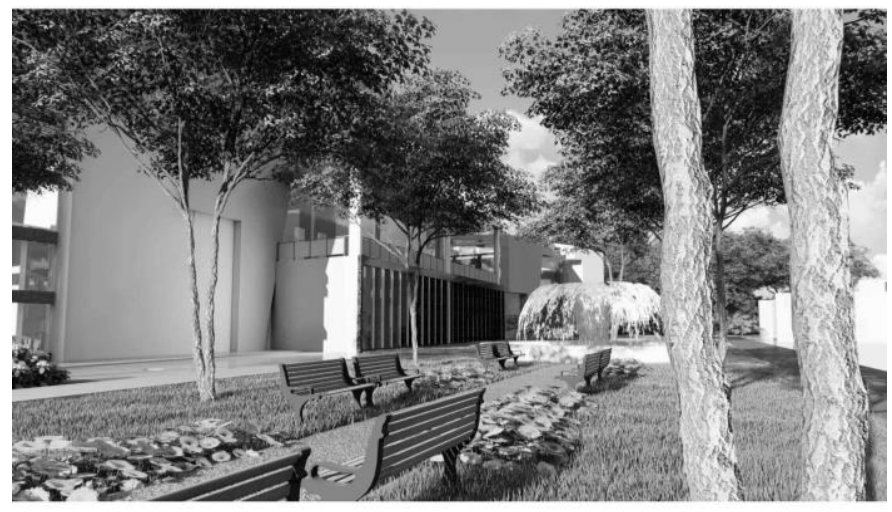

Gambar 13. Taman interaksi

\section{Lansekap}

Vegetasi dapat dimanfaatkan untuk berbagai fungsi. Pada area luar bangunan terdapat bermacam vegetasi yang dimanfaatkan sebagai elemen peneduh dan pengurang kebisingan. Pemanfaatan vegetasi terdapat pada area depan bangunan pada area parkir untuk mengurangi kebisingan dari kendaraan yang parkir. Selain itu juga dimanfaatkan pada taman di sisi barat bangunan sebagai tempat untuk berteduh.

Penyediaan ruang luar sebagai tempat untuk bersosialisasi sehingga antara pengguna bangunan juga dapat berinteraksi di luar bangunan. Seperti inetraksi yang dilakukan di taman yang dilengkapi dengan area jalan untuk jogging ataupun terapi kaki. Fungsi ruang luar sebagai tempat untuk bersosialisasi didasarkan pada perilaku anak jalanan yaitu solidaritas dan sosialiasi tinggi. (Gambar 13).

5. Sirkulasi

Sirkulasi dibedakan menjadi 2 bagian. Sirkulasi kendaraan dan sirkulasi manusia. Sirkulasi kendaraan menuju tapak diletakkan di utara di Jalan Jagir Wonokromo mendekati batas lahan sisi barat. Dimaksudkan agar pengunjung dapat mengamati dan menikmati bangunan dari luar / jalan raya. Kemudian kendaraan dapat diparkir sesuai tempat yang disediakan yang dibedakan antara pengelola dengan pengunjung bangunan. Sedangkan sirkulasi pejalan kaki didesain lebih tinggi dari sirkulasi kendaraan agar lebih aman. Selain itu juga dikarenakan pengguna bangunan tergolong usia anak - anak yang aktif dan bebas dalam bergerak (Gambar 14). Sirkulasi di dalam bangunan menggunakan tangga utama sebagai center point pengguna bangunan (Gambar 15-16). Tangga didesain lebar guna memudahkan pengguna untuk bergerak aktif dan bebas untuk naik turun menuju lantai yang diinginkan.

\section{KESIMPULAN/RINGKASAN}

Bangunan ini merupakan tempat untuk mewadahi kreatifitas anak jalanan dimana berlangsung kegiatan bisnis kerajinan tangan mulai dari produksi sampai ke pemasarannya secara online yang dapat mengembangkan karakter khusus anak jalanan (aktif dan kreatif, mandiri dan bebas, serta adaptif dengan lingkungan) melalui program pendidikan informal dan perlindungan dengan tujuan untuk memenuhi hak - hak yang dimiliki anak jalanan dalam upaya untuk bertahan hidup dan berinteraksi dengan anak nonjalanan.

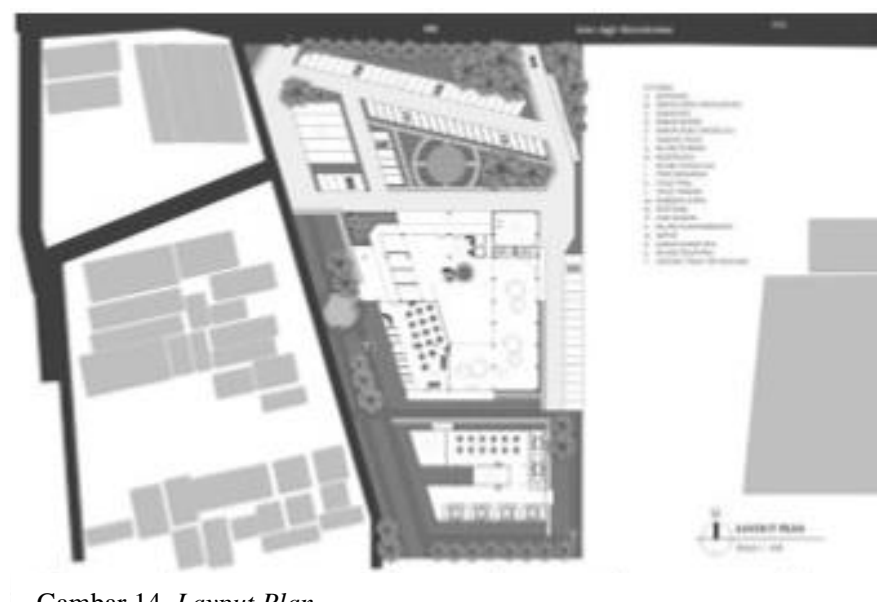

Gambar 14. Layput Plan
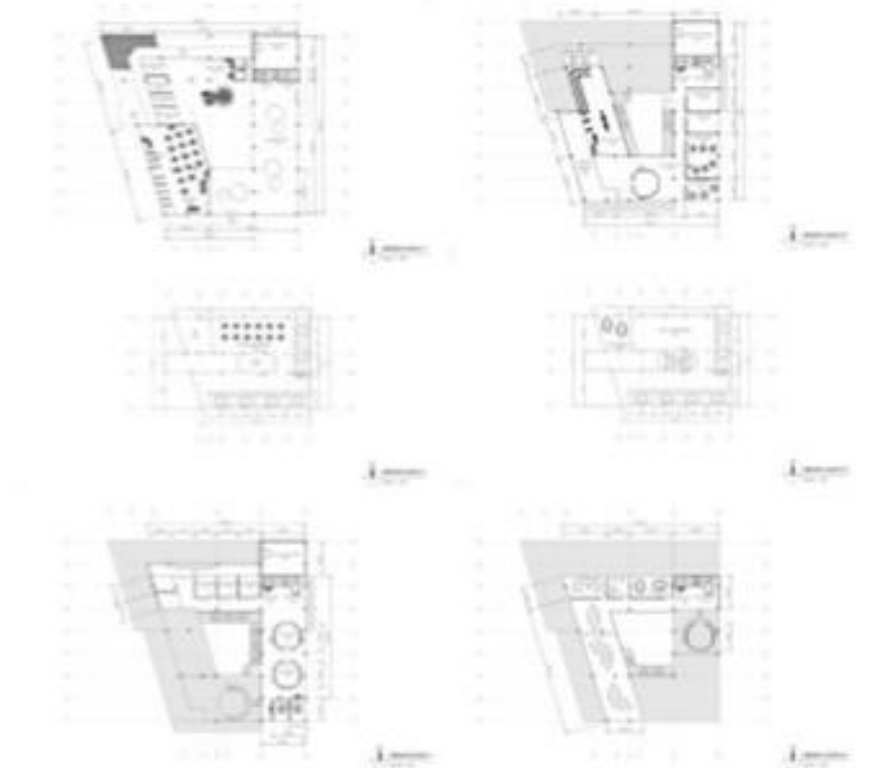

Gambar 15. Denah

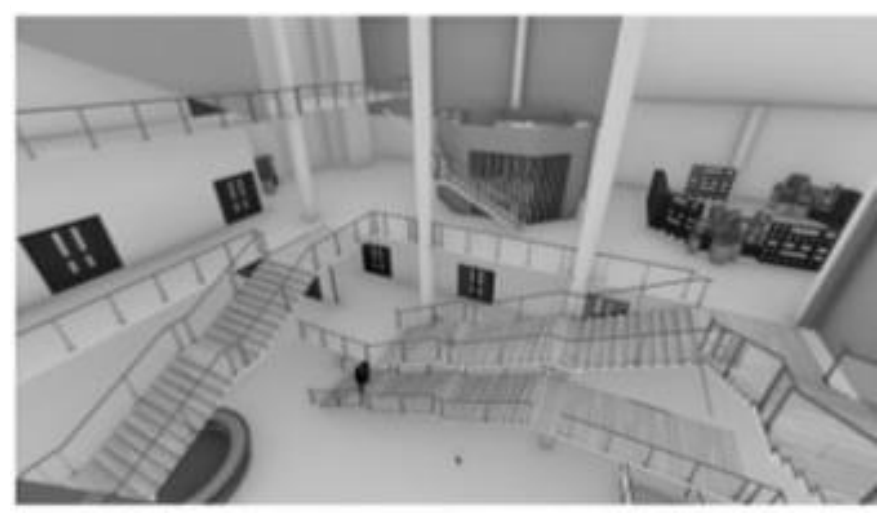

Gambar 16. Tangga sebagai center point.

Pendekatan Human Behavior diwujudkan di dalam bentuk overlapping spaces pada massa bangunan, homey pada bentuk 
bangunna, openplan pada interior ruang, tranparancy pada fasad, flexibility pada lansekap dan center point pada sirkulasi

Dengan terencananya Gedung pusat kerajinan tangan anak jalanan ini harapannya anak - anak dapat mengetahui bagaimana kehidupan anak jalanan dan dapat berinteraksi satu sama lain dalam melakukan aktivitas di dalam maupun di luar gedung.

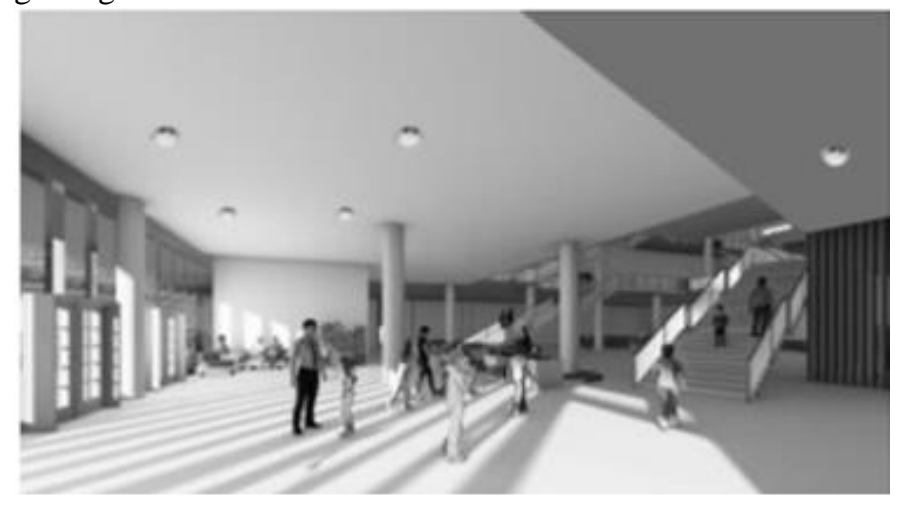

Gambar 17. Lobi utama.

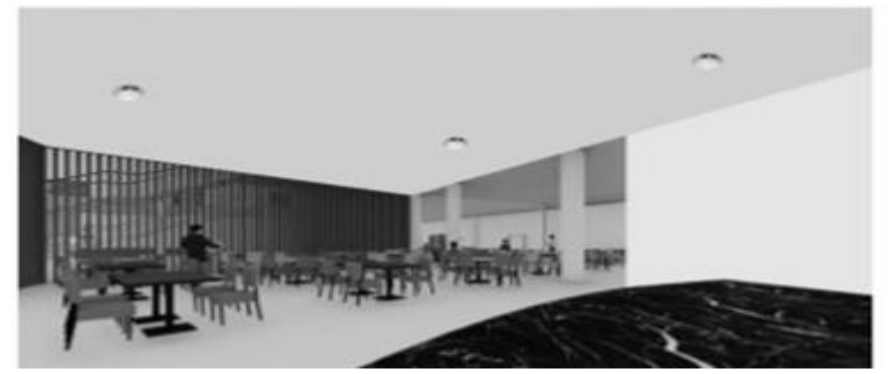

Gambar 18. Restoran.

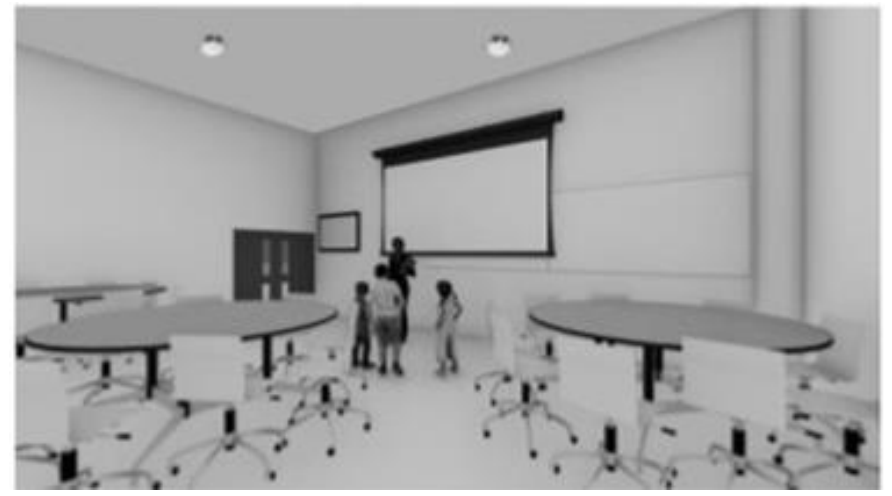

Gambar 19. Ruang kerajinan formal.

\section{UCAPAN TERIMA KASIH}

Terima kasih kepada Direktorat Pendidikan Tinggi, Departemen Pendidikan dan Kebudayaan Republik Indonesia yang telah memberikan dukungan finansial melalui Beasiswa Bidik Misi tahun 2014-2018.

\section{DAFTAR PUSTAKA}

[1] Z. Ibda, "Sekolah Non-formal dengan Pendekatan Perilaku." 2016.

[2] S. Erna, "Analisis Kebijakan Pemkot Surabaya Dalam Menangani Anak Jalanan." 2008.

[3] Z. Ibda, Apect of Human behavior, Personal, Environment and Time. Hutchion Elizabeth, 2014.

[4] P. D. Plowright, Revealing architecture design: Methods, Frameworks and Tools. New York: Routledge, 2014.

[5] A. Angelina, "Pendekatan Arsitektur Perilaku Pada Panti Werdha Di Jakarta Barat," Jakarta, 2015. 